\title{
Valoração ambiental da cachoeira da serrinha, Mariana, Minas Gerais, segundo o método de costanza (1997)
}

Description of duties and environmental valuation of natural properties of waterfall serrinha, Mariana, Minas Gerais according to the methodology to Costanza (1997)

\author{
Pedro Luiz Camargo ${ }^{1}$, Tiago Soares Barcelos², Cristiana Vieira Leocádio Rigueira ${ }^{3}$, \\ Marina de Macedo Carvalho ${ }^{4}$, Jéssica Elizabeth de Castro Dias ${ }^{5}$ \\ 1,2,3,4,5 Universidade Federal de Ouro Preto, MG, Brasil
}

\begin{abstract}
Resumo
O presente trabalho apresenta os resultados da disciplina de Valoração de Serviços Ambientais, do programa do mestrado em Sustentabilidade da UFOP. Tem como objetivo descrever as funções ambientais e estimar o valor monetário da Serrinha, área pertencente ao Parque Estadual do Itacolomi, e situada no município de Mariana, $M G$, área montanhosa, composta por rica flora e fauna. A área é utilizada pela população local para atividades de lazer e entretenimento, principalmente, por conta das cachoeiras e lagoas nela existentes. Para o desenvolvimento da pesquisa foi utilizado o método de Costanza (1997), contando com pesquisa de campo, para análise de serviços ecossistêmicos e descrição dos valores ambientais presentes, através do qual se obteve o valor estimado dos serviços ecossistêmicos da ordem de US\$34.913.550,64. Ressalta-se que o local, apesar da captação de água e de alguns sinais de incêndios recentes, encontra-se bem preservado, possuindo um potencial turístico a ser mais bem dirigido pelo poder público local.
\end{abstract}

Palavras-chave: Valoração Ecossistêmica, Serviços Ecossistêmico, Serrinha, Turismo.

\begin{abstract}
This paper presents the results of the discipline Valuation of Ecosystem Services of the Masters in Sustainability UFOP program. Aims to describe the environmental functions and estimate the monetary value of Serrinha Itacolumi area belonging to the State Park and in the municipality of Mariana, MG, mountainous area consisting of rich flora and fauna. The area is used by local people for recreation and entertainment activities, mainly due to the waterfalls and ponds in that area. To develop the research method was used to Costanza (1997), with field research for analysis of ecosystem services and Description of environmental values through which we obtained the estimated ecosystem services of U.S.\$34,913.550.64. It is noteworthy that the site, despite the uptake of water and some signs of recent fires, is well preserved, having tourist potential to be better addressed by local government
\end{abstract}

Keywords: Environmental Valuation, Environmental Economics, Serrinha, Tourism 


\section{Introdução}

O termo capital natural foi primeiro utilizado como metáfora para se referir aos recursos naturais disponíveis ao homem (TEEB, 2008). Entretanto, no final do século XX, tal termo deixou de ser apenas uma metáfora e passou a ser um conceito formal e técnico, utilizado juntamente com definições de outros tipos de capital (DALY; COOB JR., 1989).

Para Rotering (2008), apud Costanza et al.(1997), "capital" refere-se a um fator de produção oriundo de um sistema econômico ou a ativos financeiros subjacentes a estes. Portanto, pode-se pensar que "capital" será a definição dos estoques de materiais ou informações, existentes num determinado período, de maneira a produzir fluxos de serviços capazes de serem usados para transformar ou reconfigurar outros materiais, contribuindo para a melhoria do bem-estar humano (COSTANZA et al., 1997).

O capital natural, de maneira complementar à definição de "capital". pode ser entendido como o estoque de recursos naturais existentes, capazes de gerar um fluxo de serviços tangíveis e intangíveis, direta e indiretamente úteis aos seres humanos, conhecido como renda natural (COSTANZA; DALY, 1992). Tal capital, portanto, será a totalidade dos recursos, oferecidos pelo ecossistema terrestre, capazes de suportar o sistema econômico, contribuindo para o bem-estar humano.

Os estoques deste capital têm sido referidos como serviços de ecossistemas capazes de contribuir na geração de benefícios, sendo que seu valor para o sistema econômico e o bem-estar humano tem sido cada vez mais reconhecido (COSTANZA et al., 1997)

Um determinado capital natural é capaz de gerar recursos na economia, sendo estes originários de sua estrutura, como os fluxos de energia presentes e os bens ambientais que possam advir deste local. Desta forma, é possível compreender que a diminuição dos benefícios diretamente ligados aos recursos ambientais será capaz de comprometer tanto as funções do ecossistema original como os benefícios que possam ser originários destes (ANDRADE e ROMEIRO, 2009).

Dentro disto, Mueller (2007) considera que um organismo vivo e complexo pode ser considerado um sistema econômico, se este tiver relação direta com o capital natural, fator limitante do desenvolvimento econômico. Portanto, políticas capazes de uso sustentável destes capitais, visando sua otimização e consequente uso responsável, têm sido cada vez mais disseminados (COSTANZA, 2001).

O melhor uso dos recursos naturais, para Duning (1990), parte de uma proposta desenvolvimentista que combine eficiência econômica, justiça social e prudência ecológica. Esta proposta de desenvolvimento sustentável, sendo que uma de suas definições mais aceitas coloca que se trata de um modelo que atende às necessidades do presente sem comprometer a possibilidade de as ge- rações futuras atenderem a suas próprias necessidades (Comissão Mundial sobre Meio Ambiente e Desenvolvimento, 1987).

Portanto, embasado Desenvolvimento Sustentável, fica clara a necessidade de busca de uma relação viável entre natureza e desenvolvimento, sendo fundamental o entendimento de que a preservação da natureza está diretamente ligada à preservação, tanto humana quanto das demais espécies de seres vivos (ANDRADE e ROMEIRO, 2009).

Apesar de a sustentabilidade ser tratada de maneira séria dentro do campo científico, nem sempre isso tem acontecido no campo político. Lawrence Summers, por exemplo, ex- subsecretário do Tesouro dos Estados Unidos, declarou que "uma obrigação moral para com as gerações futuras demanda tratamento especial dos investimentos ambientais não passa de uma tolice (The Economist, 1992:71)".

Uma das maiores ameaças que o desenvolvimento desenfreado tem causado, em termos de impactos ao meio ambiente, é a perda de biodiversidade, colocada por Ehrlich e Ehrlich (1992:22) como "um dos mais sérios perigos ambientais singular possíveis de acontecer". Para se tentar diminuir tal perda, tanto estado quanto iniciativa privada, tem proposto, na prática, duas ações: Mecanismos de Gestão Ambiental e Políticas Públicas de Preservação de Recursos Naturais.

Depender somente do mercado financeiro para se equilibrar a eficiência econômica e preservação ambiental é algo inviável, e neste contexto que surge um mecanismo de gestão capaz de influenciar nas Políticas Públicas de Preservação de Recursos Naturais, a gestão ambiental. Esta estrutura é importante por permitir que tanto legislações adequadas quanto mecanismos econômicos possam frear o desenvolvimento desordenado. Sobre esta dicotomia entre a eficiência econômica $X$ preservação ambiental, Mota (2006, p. 129) conclui:

A finalidade dos instrumentos econômicos é proporcionar os melhores resultados em termos de eficácia ambiental e de eficiência econômica, tendo como objetivo assegurar um preço apropriado para os recursos ambientais, de forma a promover seu uso e alocação, o que permite garantir os ativos/serviços ambientais tratamento similar aos demais fatores de produção.

Um mecanismo de gestão, comprometido com a preservação dos recursos naturais, deve também contribuir para a manutenção dos serviços e funções ambientais que um ecossistema é capaz de oferecer. Para Daly e Farley, (2004) as funções ecossistêmicas são as diferentes estruturas presentes e ligadas entre os mais diferentes indivíduos de um ecossistema. São exemplos disso a ciclagem de nutrientes e o ciclo da água.

Já para Daily (1997), os serviços ambientais serão as benesses diretas e indiretas que o ser humano pode obter com a preservação de tais locais, como a provisão 
de alimentos e a regulação climática. Portanto, para se manter as funções e serviços de um determinado ecossistema, é fundamental não só os mecanismos de gestão ambiental, como também o comprometimento do poder público.

No campo das Políticas Públicas de Preservação de Recursos Naturais, tendo como ênfase principal a proposta de se evitar a perda tanto do capital natural quanto da biodiversidade em si, que o Brasil adotou a Política Nacional de Meio Ambiente (PNMA) (Lei 6938/81) Para Mirra (2006) apud Bechara (2009), esta seria uma forma de diminuir ou evitar prejuízos causados pelos danos ambientais.

Uma das formas mais usuais de se prever esta situação perpassa pela Valoração Ambiental, que pode ser compreendida como a mensuração pecuniária de recursos ambientais, a ser feita de maneira a interromper uma determinada degradação ambiental antes que esta ultrapasse o limite da irreversibilidade (CASIMIRO FILHO, 1999). Para tanto, não se faz necessário o comércio do bem natural, mas, sim, verificar quanto as pessoas estão dispostas a pagar para ter o serviço ambiental (SEILD; SAMPAIO, 2009).

Este "contrato de pagamentos por serviços ambientais" seria uma forma de levar, aos componentes naturais, uma contabilidade econômica, contribuindo para preservação destes, especialmente nos Parques Nacionais e Estaduais.

Para o Instituto Estadual de Florestas de Minas Gerais (IEF-MG), o objetivo de um Parque Estadual é:

... a preservação de ecossistemas naturais de grande relevância ecológica e beleza cênica, possibilitando a realização de pesquisas científicas e o desenvolvimento de atividades de educação e interpretação ambiental, de recreação em contato com a natureza e de turismo ecológico. Pertence à categoria de unidades de conservação de proteção integral e é de posse e domínio públicos. (IEF, 2013)

Entre os Parques Estaduais de Minas Gerais, um dos que merecem destaque é o Parque Estadual do Itacolomi, localizado entre Ouro Preto e Mariana, e criado em 14 de junho de 1967, pela Lei no 4.495 (IEF, 2013). Possuindo uma área de 7.543 hectares, este parque possui grande relevância cênica e de biodiversidade para ambas as cidades.

Especificamente na parte norte do Parque, localizado em Mariana, está presente a área da Cachoeira da Serrinha, muito frequentada por banhistas e turistas, mas que não possui cercamento ou mesmo vigilância por parte do IEF, sendo, portanto, muito afetada pela proximidade com o bairro Santa Rita de Cássia e com o distrito de Passagem de Mariana, ocorrendo frequentes incursões não autorizadas. Este local é também onde ocorre a captação de água feita pela Prefeitura de Mariana (TAFURI, 2008).

Portanto, tendo como base o pressuposto apresentado acerca de porque se valorar um bem natural, propõe-se neste artigo estimar o valor dos serviços ecossistêmicos da Serrinha em Mariana - MG, descrevendo suas funções ambientais e possíveis pressões antrópicas, de acordo com metodologia de Constanza (1997).

\section{Metodologia}

Este trabalho foi realizado na área que envolve a Cachoeira da Serrinha, vetor norte do Parque Estadual do Itacolomi (PEIT), dentro do município de Mariana, MG. Por entender que os serviços ecossistêmicos providos pelo PEIT exercem efeitos benéficos ao município em que o contingente do entorno está sob os efeitos providos por esta reserva.

Para análise valorativa, primeiramente, houve a identificação dos serviços ecossistêmicos e das pressões antrópicas, de acordo com a proposição do TEEB (2008), sigla em inglês para "The Economics of Ecosystems and Biodiversity", conhecido no Brasil como A Economia dos Ecossistemas e da Biodiversidade. Tal metodologia propõe quatro categorias de serviços: Regulação; Habitat; Amenidades e Cultura e Abastecimento.

Em relação ao valor monetário dos serviços ecossistêmicos da Cachoeira da Serrinha, utilizou-se a tabela proposta por Constanza et al (1997), que estimou o valor dos ecossistemas e da biodiversidade providos pelo meio ambiente em nível global, sendo possível, através destes dados, realizar a transposição destes valores do plano global ao local.

\section{1 Área de Estudo}

O Município de Mariana está localizado na região central de Minas Gerais, Zona Metalúrgica/Campo das Vertentes, integrando com outros 22 municípios a micro região 187 - Espinhaço Meridional. Geograficamente, a cidade está situada entre os meridianos $43^{\circ} 05^{\prime} 00^{\prime \prime}$

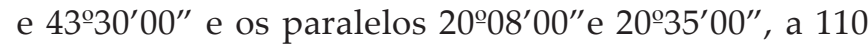
quilômetros da capital Belo Horizonte, tendo como comprimento em extensão os municípios de Catas Altas $(29,13 \mathrm{~km})$ e Alvinópolis $(41,68 \mathrm{~km})$, a norte, Barra Longa $(30,68 \mathrm{~km})$ e Acaiaca $(19,61 \mathrm{~km})$ a leste, Ouro Preto $(67,71 \mathrm{~km})$ a oeste, Piranga $(16,30 \mathrm{~km})$ e Diogo de Vasconcelos $(39,77 \mathrm{~km})$ a sul (RBC - Revista Brasileira de Cartografia №. 57/03, 2005) e possui uma área total de 1.193,293 km² (IBGE, 2008).

Mariana possui um clima tropical de altitude com uma estação chuvosa, que vai de outubro a março, e outra seca, no restante do ano. Sua vegetação varia com a altitude, ocorrendo, na região, remanescentes de Mata Atlântica, assim como diversas fisionomias de Cerrado (AB'SABER, 1977; RIZZINI, 1979).

O PEIT foi criado em 14 de junho de 1967, pela Lei Estadual no 4.495. O Parque Estadual do Itacolomi está inserido na porção sul da Reserva da Biosfera da Serra 




Figura 2: Foto de satélite com o percurso entre o distrito de Passagem e a área da Cachoeira da Serrinha.

Tabela 1: Legenda da Figura 1

\begin{tabular}{|c|l|}
\hline $\mathbf{N}^{\circ}$ & Descrição \\
\hline 124 & Ponto de Partida para o Percurso \\
\hline 125 & Trevo do Distrito de Passagem de Mariana \\
\hline 126 & Ponto de Captação de Água para a Cidade de Mariana \\
\hline 127 & Lagoa Véu da Noiva 1 \\
\hline 128 & Lagoa Véu da Noiva 2 \\
\hline 129 & Lagoa do Estudante \\
\hline 143 & Lagoa dos Patos \\
\hline 144 & Lagoa Negra \\
\hline
\end{tabular}

do Espinhaço e a sudeste do Quadrilátero Ferrífero. A região caracteriza-se por ser uma zona de transição entre a Floresta Atlântica e o Cerrado, com relevo acidentado (Plano de Manejo, IEF, 2013).

A cachoeira da Serrinha possui uma área total de 6,587 $\mathrm{km}^{2}$ ou 658,7 ha (SAAE, 2012) e localiza-se na porção que envolve o município de Mariana com acesso pelo distrito de "Passagem", encontrando-se distante cerca de 4,5 km da área urbana mais próxima (SAAE, 2012).

A área engloba cinco pequenas lagoas: Lagoa do
Estudante (23K 0662749, UTM 7742081, 1023 m); Lagoa Negra (23K 066 2598, UTM 7742145, 1035 m); Lagoa dos Patos (23K 06626 33, UTM 774 2101, 1050 m); Véu da Noiva 1 (23K 066 2548, UTM 7742164, 1043 m) e Véu da Noiva 2 (23 K 066 2481, UTM 7742130, 1066m) (Figura 1). A água oriunda destas lagoas vão desembocar no Córrego Belchior, rio responsável por alimentar a maior parte da população da cidade de Mariana. 


\subsection{Técnica da Extrapolação Inversa de Robert Constanza (1997)}

A metodologia TEEB, sigla em inglês para "The Economics of Ecosystems and Biodiversity", ficou conhecida no Brasil como Economia dos Ecossistemas e da Biodiversidade. Tal metodologia propõe que a biodiversidade tenha um preço, dessa forma, um determinado estudo introduz, na biodiversidade e nos seus serviços, as alternativas de ação dos agentes do mercado financeiro diante de um cenário de escassez dos recursos naturais. Assim, dá-se valor a cada um dos elementos da biodiversidade, como florestas, ciclo da água, etc. colocados à disposição pela natureza.
De forma geral, os trabalhos com tal metodologia utilizam a tabela proposta por Constanza et al (1997). Este autor é um economista ecológico da Universidade de Maryland, nos Estados Unidos, que, se utilizando do método de valoração contingente, estimou o valor de 17 principais "serviços" oferecidos pelo meio ambiente (Tabela 2), tais como a oferta de oxigênio, captura de carbono, oferta de água, de produtos medicinais e alimentos, em 11 grandes ecossistemas no mundo (Tabela 3) Cabe destacar que tal proposta, apesar de empírica, é uma forma de se mensurar valores potenciais de serviços ecossistêmicos (CONSTANZA, 1998).

Tabela 2: Funções e Serviços Ecossistêmicos utilizados por Constanza (Adaptado de COSTANZA et al, 1997).

\begin{tabular}{|c|c|c|c|}
\hline $\mathbf{N}^{\circ}$ & Serviço Ambiental & Função Ambiental & Exemplos \\
\hline 1 & Regulação de Gás & $\begin{array}{l}\text { Regulação da composição } \\
\text { quimica da atmosfera }\end{array}$ & $\begin{array}{l}\text { Balanço do } \mathrm{CO}_{2} / \mathrm{O}_{2^{\prime}} \mathrm{O}_{3} \text { para proteção } \\
\text { contra raios } \mathrm{UV} \mathrm{B} \text {, e niveis de SOx. }\end{array}$ \\
\hline 2 & Regulação do Clima & $\begin{array}{l}\text { Regulação da temperatura e } \\
\text { precipitação }\end{array}$ & $\begin{array}{l}\text { Regulação dos gases do efeito estufa, } \\
\text { produção de dimetilsulfeto que afeta a } \\
\text { formação de nuvens. }\end{array}$ \\
\hline 3 & $\begin{array}{l}\text { Regulação de } \\
\text { Distúrbios }\end{array}$ & $\begin{array}{l}\text { Capacitação de } \\
\text { amortecimento em resposta } \\
\text { ao clima }\end{array}$ & $\begin{array}{l}\text { Proteção contra tormentas, controle } \\
\text { de inundações, recuperação de secas e } \\
\text { outros aspectos da resposta dos habitats } \\
\text { à variabilidade ambiental, controlada } \\
\text { principalmente pela estrutura vegetal. }\end{array}$ \\
\hline 4 & Regulação da Água & $\begin{array}{l}\text { Regulação dos fluxos } \\
\text { hidrologicos }\end{array}$ & $\begin{array}{l}\text { Oferta de água para usos agrícola } \\
\text { (irrigação) industrial (fábricas) ou para } \\
\text { transporte. }\end{array}$ \\
\hline 5 & $\begin{array}{l}\text { Ábastecimento de } \\
\text { Água }\end{array}$ & $\begin{array}{l}\text { Armazenamento e } \\
\text { conservação de água }\end{array}$ & $\begin{array}{l}\text { Oferta de água por bacias hidrográficas, } \\
\text { reservatórios e aquíferos. }\end{array}$ \\
\hline 6 & Controle de Erosão & Retenção de solo & $\begin{array}{l}\text { Prevenção da perda de solo pelo vento, } \\
\text { escorrimento superficial e outros } \\
\text { processos de remoção, armazenagem de } \\
\text { areia em lagos e áreas úmidas. }\end{array}$ \\
\hline 7 & Formação do Solo & $\begin{array}{l}\text { Processo de formação do } \\
\text { solo }\end{array}$ & $\begin{array}{l}\text { Decomposição de rochas e acumulação } \\
\text { de material orgânico. }\end{array}$ \\
\hline 8 & Ciclo de Nutrientes & $\begin{array}{l}\text { Armazenamento e } \\
\text { o processamento de } \\
\text { nutrientes }\end{array}$ & $\begin{array}{l}\text { Fixação de nitrogênio, fósforo, potássio } \\
\text { e outros elementos ou ciclos de } \\
\text { nutrientes. }\end{array}$ \\
\hline 9 & $\begin{array}{l}\text { Tratamento de } \\
\text { Resíduos }\end{array}$ & $\begin{array}{l}\text { Recuperação de nutrientes } \\
\text { celulares }\end{array}$ & $\begin{array}{l}\text { Tratamento de resíduos, controle de } \\
\text { poluição, detoxificação. }\end{array}$ \\
\hline
\end{tabular}


Tabela 2: continuação...

\begin{tabular}{|c|c|c|c|}
\hline $\mathbf{N}^{\circ}$ & Serviço Ambiental & Função Ambiental & Exemplos \\
\hline 10 & Polinização & Movimento de gametas florais & $\begin{array}{l}\text { Suporte a polinizadores para a } \\
\text { reprodução das populações de } \\
\text { plantas. }\end{array}$ \\
\hline 11 & Controle Biológico & Regulação trófica de populações & $\begin{array}{l}\text { Controle das espécies de presas } \\
\text { por predadores-chave, redução da } \\
\text { herbivoria por predadores do topo } \\
\text { da cadeia. }\end{array}$ \\
\hline 12 & Refúgio & $\begin{array}{l}\text { Habitat para populações residentes } \\
\text { e transitórios }\end{array}$ & $\begin{array}{l}\text { Berçários, habitats para espécies } \\
\text { migratórias e locais, habitats para } \\
\text { espécies capturadas localmente ou } \\
\text { durante os períodos de inverno. }\end{array}$ \\
\hline 13 & $\begin{array}{l}\text { Produção de } \\
\text { Comida }\end{array}$ & $\begin{array}{l}\text { Produção primária bruta extraída } \\
\text { como alimento }\end{array}$ & $\begin{array}{l}\text { Produção de pescado, caça, grãos, } \\
\text { sementes e frutas através da } \\
\text { pesca, caça, coleta e agricultura de } \\
\text { subsistência. }\end{array}$ \\
\hline 14 & Matéria Prima & $\begin{array}{l}\text { Produção primária bruta extraída } \\
\text { como matérias-primas }\end{array}$ & $\begin{array}{l}\text { Produção de madeira, lenha ou } \\
\text { forragem. }\end{array}$ \\
\hline 15 & Recursos Genéticos & $\begin{array}{l}\text { Fonte de matérias e produtos } \\
\text { únicos }\end{array}$ & $\begin{array}{l}\text { Medicamentos, produtos para } \\
\text { pesquisas em materiais, genes para } \\
\text { resistência a patógenos de plantas } \\
\text { e pestes de culturas, espécies } \\
\text { ornamentais. }\end{array}$ \\
\hline 16 & Recreação & Oportunidade de recreação & $\begin{array}{l}\text { Ecoturismo, pesca esportiva e } \\
\text { outras atividades recreativas ao ar } \\
\text { livre. }\end{array}$ \\
\hline 17 & Cultura & $\begin{array}{l}\text { Oportunidade para usos não } \\
\text { comerciais }\end{array}$ & $\begin{array}{l}\text { Valores estéticos, artísticos, } \\
\text { educacionais, espirituais e/ou } \\
\text { científicos dos ecossistemas. }\end{array}$ \\
\hline
\end{tabular}

Tabela 3: Relação dos Grupos e Funções Ambientais segundo De Groot et al. (1992).

\begin{tabular}{|l|l|}
\hline $\begin{array}{l}\text { Grupos de Funções } \\
\text { Ambientais }\end{array}$ & $\begin{array}{l}\text { Funções Ambientais Percebidas na Área de Estudo } \\
\text { Funções de Regulação }\end{array}$ \\
\hline $\begin{array}{l}\text { Regulação do Clima, Regulação de Distúrbios, Regulação da } \\
\text { Água, Abastecimento de Água, Controle de Erosão, Formação do } \\
\text { Solo, Ciclo de Nutrientes, Tratamento de Resíduos, Polinização, } \\
\text { Controle Biológico, Refúgio. }\end{array}$ \\
\hline Funções de Provisão & Recreação \\
\hline Funções de Produção & $\begin{array}{l}\text { Regulação de Gás, Produção de Comida, Matéria Prima, Recursos } \\
\text { Genéticos. }\end{array}$ \\
\hline Funções de Informação & Cultura \\
\hline
\end{tabular}


O valor monetário global estimado para os recursos e serviços ambientais do planeta variou, segundo Constanza, na faixa de US\$ 06 - 54 trilhões/ano, o que resultou no valor médio de US\$ 33 trilhões/ano. Os banhados ou terras úmidas foram considerados os ecossistemas mais valiosos, fornecendo serviços ambientais avaliados em US\$14.785,00/ha-ano. Para Constanza (1998), os serviços ambientais do oceano valem cerca de US\$ 252,00 e a floresta tropical US\$2.007/ano. Algo em torno de $63 \%$ do valor (US\$20,9 trilhões) global dos recursos

Tabela 4: Tabela TEEB de Funções Ambientais.

\begin{tabular}{|c|c|c|c|c|c|c|c|}
\hline Bioma & $\begin{array}{c}\text { Area } \\
\left(\text { há } \times 10^{8}\right)\end{array}$ & $\begin{array}{l}\text { Regulação } \\
\text { de gás }\end{array}$ & $\begin{array}{l}\text { Regulação do } \\
\text { clima }\end{array}$ & $\begin{array}{l}\text { Regulação de } \\
\text { pertubações }\end{array}$ & $\begin{array}{l}\text { Regulação } \\
\text { da água }\end{array}$ & $\begin{array}{l}\text { Suprimento } \\
\text { de água }\end{array}$ & $\begin{array}{l}\text { Controle de } \\
\text { erosão }\end{array}$ \\
\hline 1. Marinho & 36302 & & & & & & \\
\hline 1.1 Oceano Aberto & 33200 & 38 & & & & & \\
\hline 1.2 Costa & 3102 & & & 88 & & & \\
\hline 1.2.1 Estuário & 180 & & & 567 & & & \\
\hline 1.2.2 Alga marinha/ Camas de alga & 200 & & & & & & \\
\hline 1.2.3 Recife de coral & 62 & & & 2750 & & & \\
\hline 1.2.4 Cinturão & 2660 & & & & & & \\
\hline 2. Terrestre & 15323 & & & & & & \\
\hline 2.1 Florestas & 4855 & & 141 & 2 & 2 & 3 & 96 \\
\hline 2.1.1 Tropical & 1900 & & 223 & 5 & 6 & 8 & 245 \\
\hline 2.1.2 Temperada/boreal & 2955 & & 88 & & 0 & & \\
\hline 2.2 Grama e pastagem natural & 3989 & 7 & 0 & & 3 & & 29 \\
\hline 2.3. Pantanal & 330 & 133 & & 4539 & 15 & 3800 & \\
\hline 2.3.1 Tidal marsh/Mangue & 165 & & & 1839 & & & \\
\hline 2.3.2 Pantano florestal/Floodplains & 165 & 265 & & 7240 & 30 & 7600 & \\
\hline 2.4 Lagos e rios & 200 & & & & 5445 & 2117 & \\
\hline 2.5 Deserto & 1925 & & & & & & \\
\hline 2.6 Tundra & 743 & & & & & & \\
\hline 2.7 Gelo e rocha & 1640 & & & & & & \\
\hline 2.8 Terra cultivada & 1400 & & & & & & \\
\hline 10. Urbano & 332 & & & & & & \\
\hline Total & 51625 & 1341 & 684 & 1779 & 115 & 1692 & 576 \\
\hline
\end{tabular}


Continuação da Tabela 4.

\begin{tabular}{|c|c|c|c|c|c|c|c|c|}
\hline Bioma & $\begin{array}{c}\text { Area } \\
\left(\text { há } \times 10^{8}\right)\end{array}$ & $\begin{array}{l}\text { Formação } \\
\text { do solo }\end{array}$ & $\begin{array}{l}\text { Ciclos dos } \\
\text { nutrientes }\end{array}$ & $\begin{array}{l}\text { Tratamento } \\
\text { de residuos }\end{array}$ & Polinização & $\begin{array}{l}\text { Controle } \\
\text { biológico }\end{array}$ & $\begin{array}{c}\text { Habitat e } \\
\text { refúgios }\end{array}$ & $\begin{array}{l}\text { Produção } \\
\text { de comida }\end{array}$ \\
\hline 1. Marinho & 36302 & & & & & & & \\
\hline 1.1 Oceano Aberto & 33200 & & 118 & & & 5 & & 15 \\
\hline 1.2 Costa & 3102 & & 3677 & & & 38 & 8 & 93 \\
\hline 1.2.1 Estuário & 180 & & 21100 & & & 78 & 131 & 521 \\
\hline $\begin{array}{l}\text { 1.2.2 Alga marinha/ } \\
\text { Camas de alga }\end{array}$ & 200 & & 19002 & & & & & \\
\hline 1.2.3 Recife de coral & 62 & & & 58 & & 5 & 7 & 220 \\
\hline 1.2.4 Cinturão & 2660 & & 1431 & & & 39 & & 68 \\
\hline 2. Terrestre & 15323 & & & & & & & \\
\hline 2.1 Florestas & 4855 & 10 & 361 & 87 & & 2 & & 43 \\
\hline 2.1.1 Tropical & 1900 & 10 & 922 & 87 & & & & 32 \\
\hline 2.1.2 Temperada/boreal & 2955 & 10 & & 87 & & 4 & & 50 \\
\hline $\begin{array}{l}2.2 \text { Grama e pastagem } \\
\text { natural }\end{array}$ & 3989 & 1 & & 87 & 25 & 23 & & 67 \\
\hline 2.3. Pantanal & 330 & & & 4177 & & & 304 & 256 \\
\hline 2.3.1 Tidal marsh/Mangue & 165 & & & 6696 & & & 169 & 466 \\
\hline $\begin{array}{l}\text { 2.3.2 Pantano florestal/ } \\
\text { Floodplains }\end{array}$ & 165 & & & 1659 & & & 439 & 47 \\
\hline 2.4 Lagos e rios & 200 & & & 665 & & & & 41 \\
\hline 2.5 Deserto & 1925 & & & & & & & \\
\hline 2.6 Tundra & 743 & & & & & & & \\
\hline 2.7 Gelo e rocha & 1640 & & & & & & & \\
\hline 2.8 Terra cultivada & 1400 & & & & 14 & 24 & & 54 \\
\hline 10. Urbano & 332 & & & & & & & \\
\hline Total & 51625 & 53 & 17075 & 2277 & 117 & 417 & 124 & 1386 \\
\hline
\end{tabular}


Continuação da Tabela 4.

\begin{tabular}{|c|c|c|c|c|c|c|c|}
\hline Bioma & $\begin{array}{c}\text { Area (há } \\
\left.\times 10^{8}\right)\end{array}$ & $\begin{array}{l}\text { Matérias } \\
\text { primas }\end{array}$ & $\begin{array}{l}\text { Recursos } \\
\text { genéticos }\end{array}$ & Recreação & Cultura & $\begin{array}{l}\text { Valor total per há } \\
\qquad\left(\$ h a^{-1} \mathrm{yr}^{-1}\right)\end{array}$ & $\begin{array}{l}\text { Valor total do fluxo } \\
\text { global }\left(\$ y r^{-1} \times 10^{9}\right)\end{array}$ \\
\hline 1. Marinho & 36302 & & & & & 577 & 20949 \\
\hline 1.1 Oceano Aberto & 33200 & 0 & & & 76 & 76 & 8381 \\
\hline 1.2 Costa & 3102 & 4 & & 82 & 62 & 148 & 12568 \\
\hline 1.2.1 Estuário & 180 & 25 & & 381 & 29 & 435 & 4110 \\
\hline 1.2.2 Alga marinha/ Camas de alga & 200 & 2 & & & & 2 & 3801 \\
\hline 1.2.3 Recife de coral & 62 & 27 & & 3008 & 1 & 3036 & 375 \\
\hline 1.2.4 Cinturão & 2660 & 2 & & & 70 & 72 & 4283 \\
\hline 2. Terrestre & 15323 & & & & & 804 & 12319 \\
\hline 2.1 Florestas & 4855 & 138 & 16 & 66 & 2 & 222 & 4706 \\
\hline 2.1.1 Tropical & 1900 & 315 & 41 & 112 & 2 & 470 & 3813 \\
\hline 2.1.2 Temperada/boreal & 2955 & 25 & & 36 & 2 & 63 & 894 \\
\hline 2.2 Grama e pastagem natural & 3989 & & 0 & 2 & & 2 & 906 \\
\hline 2.3. Pantanal & 330 & 106 & & 574 & 881 & 1561 & 4879 \\
\hline 2.3.1 Tidal marsh/Mangue & 165 & 162 & & 658 & & 820 & 1648 \\
\hline 2.3.2 Pantano florestal/Floodplains & 165 & 49 & & 491 & 1761 & 2301 & 3231 \\
\hline 2.4 Lagos e rios & 200 & & & 230 & & 230 & 1700 \\
\hline 2.5 Deserto & 1925 & & & & & & \\
\hline 2.6 Tundra & 743 & & & & & & \\
\hline 2.7 Gelo e rocha & 1640 & & & & & & \\
\hline 2.8 Terra cultivada & 1400 & & & & & 92 & 128 \\
\hline 10. Urbano & 332 & & & & & & \\
\hline Total & 51625 & 721 & 79 & 815 & 3015 & 10911 & 33268 \\
\hline
\end{tabular}


foi atribuído aos ecossistemas marinhos, sendo que a metade deste valor refere-se às áreas costeiras. No grupo dos hábitats terrestres, as florestas foram avaliadas em US $\$ 4,7$ trilhões, os banhados em US $\$ 4,9$ trilhões, os ciclos de nutrientes em US $\$ 17$ trilhões/ano, e os serviços ambientais ao nível máximo foram valorados em US\$54 trilhões/ano (NETO, 2010).

A técnica de Valoração Ambiental, apresentada por Constanza, perpassa pelo entendimento de que o capital natural é a função base do ecossistema local, função esta já identificada por outros autores como Turner (1988) e De Groot (1987; 1992)1', ou seja, pelo uso da energia solar, somado à taxa fotossintética, é que ocorrem todos os ecosserviços e fluxos energéticos dos sistemas naturais, como se pode observar na Tabela 3 (DE GROOT et al. 1992).

Segundo Constanza (1994), o valor que estes recursos naturais podem ter está condicionado, de maneira direta, ao valor anual dos ecosserviços diminuído pela taxa de desconto que possa estar presente, pois é através desta equação (serviço ecológico dividido pela taxa de desconto) que se calcula o valor econômico de um ecossistema. Tal abordagem não é nova, tendo sido utilizada por este e outros autores em outros trabalhos (CONSTANZA et al, 1997; BALMFORD et al, 2002).

Resumidamente, tal técnica consiste em obter o valor aproximado dos ecosserviços de uma área, realizando-se a extrapolação inversa (de nível global ao nível local) dos resultados da pesquisa internacional (COSTANZA et. al, 1997), para todos os serviços ambientais da região estudada, como pode ser observado na Tabela 4.

Para a estimativa do valor monetário da área que envolve a Cachoeira da Serrinha, consideraram-se os dezessete serviços ecossistêmicos descritos, porém, relativos às Pastagens, Lagos e Florestas tropicais, por serem estes os biomas presentes no local. Cabe destacar, ainda, que a área é suporte para atividades de entretenimento e lazer nos finais de semana e feriados, e, portanto, sendo os recursos hídricos e a pastagem de largo usufruto. Soma-se, ainda, o fato de a área ser circundada por cobertura vegetal natural pertencente ao Parque Estadual do Itacolomi. Por essas razões, estes elementos da paisagem destacam-se no cenário de percepção socioambiental, sendo objeto do estudo que ora se apresenta.

Para melhor entendimento dos cálculos e resultados, o tópico 4, Discussões, foi dividido em três subitens: Pressões Antrópicas, Funções Ambientais e Cálculo do Valor Ambiental, segundo a Metodologia TEEB.

1 De Groot merece um destaque especial por ter sido o primeiro a propor a divisão das funções ambientais em 4 categorias: a) regulação; b) habitat; c) produção; e d) informação; algo que seria melhor aproveitado e estudado depois por outros autores, especialmente Constanza (1994).

\section{4- Resultados e discussões}

\subsection{Pressões Antrópicas}

Considera-se pressão antrópica toda modificação, ou alteração, ocorrida em um meio natural que possa, inclusive, causar algum tipo de impacto (IEF-MG, 2013). Nos trabalhos de Tafuri (2008) e Oliveira Júnior et al (2012), relataram-se alguns impactos identificados neste estudo, além de outros, explanados ao longo deste tópico.

\section{a- Presença de Animais Exóticos}

O primeiro dos impactos observados se deu em cima do grande número de animais domésticos (pastagem inclusive) presentes no local, nadando e defecando próximo à água usada por banhistas. Bois sendo criados na área do PEIT é um antigo costume dos pequenos empresários locais, hábito cultural difícil de ser combatido.

Tal prática, além de ser ilegal, pode causar diversas doenças, tendo em vista o uso recreativo das águas, exemplo disso é a brucelose (Streptococcus pyogenes), possível de ser contraída pelo contato direto entre o gado doente ou água contaminada por estes (MORENO, 2002).

\section{b- Invasão}

Outro tipo de pressão antrópica que merece destaque são as moradias. A falta de fiscalização no entorno acaba por permitir ocupações irregulares na parte marianense do PEIT, especialmente no bairro Cabanas, uma área de aproximadamente $10 \mathrm{~km}$ de área do PEIT, que começou a ser ocupado há cerca de 20 anos atrás, transformandose no principal bairro da cidade, sendo um dos maiores da região (IBGE, 2012).

Segundo estimativas do IBGE para 2014 (IBGE, 2012), este bairro possui mais de 20.000 pessoas, sendo que, como a maior parte da cidade de Mariana, não possui saneamento básico, gerando uma vertente de lixo urbano que impacta de maneira significativa à área da Serrinha, especialmente em seu entorno, tendo em vista que a coleta de lixo não ocorre em todas as ruas do bairro.

Cabe lembrar, ainda acerca deste tema, que o bairro mencionado se encontra em expansão, aumentando ainda mais o impacto antrópico sobre a biodiversidade presente no vetor norte do PEIT. Se o crescimento urbano do local permanecer como se apresenta, em breve o bairro estará definitivamente na área da Serrinha, ou seja, dentro dos limites do PEIT.

Os impactos ambientais descritos, somados ao limitado grau de instrução (tanto dos moradores como dos visitantes), geram mais um problema a ser combatido: os resíduos sólidos, que causam significativo impacto visual e ecossistêmico ao local.

\section{c- Incêndios e Retirada de Plantas para uso Gastro- nômico e Ornamental}

Pequenos e recentes incêndios também foram observados nas visitas aos locais de estudo e a causa para 
isso (segundo relatos de moradores do entorno) está relacionada tanto à retirada de lenha para uso doméstico quanto à extração do Broto de Samambaia (Pteridium aquilinum), utilizado na culinária local, pois este vegetal se reproduz rapidamente, sem espécies que venham a competir com ele por um determinado substrato, algo comum em pteridófitas (EVERETT, 2000).

Outro fator observado, e de impacto local, é a coleta de orquídeas, especialmente as espécies Bifrenaria thyrianthina Reichb.; Bulbophyllum weddellii Reichb; Cleistes lepida (Reichb.F.), que são facilmente identificadas pelos moradores e visitantes do entorno.

Tanto as flores como o Broto de Samambaia são fonte de renda, uma vez que a população da área comercializa tais flores na estrada (BR 262), ou mesmo para colecionadores, enquanto o Broto de Samambaia costuma ser vendido de porta em porta, com o maço tendo o valor médio de $\mathrm{R} \$ 5,00$. Ou seja, grande parte dos moradores do entorno têm, na Serrinha, uma de suas principais formas de subsistência, seja na extração de lenha para uso particular, seja na comercialização de seus bens naturais.

\section{d- Segurança}

Destaca-se também, como observado nos outros vetores do PEIT, a falta de segurança na área de captação de água. No local, encontra-se o duto responsável por conduzir a maior parte da água a ser consumida pela população marianense. Mesmo assim, o local não possui as mínimas condições de higiene e segurança: as tubulações estão, em sua maioria, enferrujadas e rompidas, aumentando o risco de contaminação e desperdício de água.

Ainda acerca da captação, não se encontrou estudos que embasem a interceptação hídrica do Córrego Belchior. O ideal seriam estudos hidrológicos históricos para determinação do Q7/10 (vazão mínima de duração de sete dias com recorrência de 10 anos), como orientam as leis reguladoras.

A ETA Sul (SAAE, 2013) possui capacidade de 70 1/s, tendo uma estação elevatória para o armazenamento de água de lavagem dos filtros. Esta ETA se localiza em Passagem de Mariana e é responsável pelo abastecimento de três bairros de Mariana (São Gonçalo, Vila do Carmo, Santo Antônio), o reservatório Monsenhor Horta, que redistribui água para a Rua do Catete, Centro Histórico e o Hospital local, sendo que, quando necessário, também o bairro Estrela do Sul. Em resumo, a ETA Sul é responsável por garantir água potável para cerca de 30 mil pessoas, que é o número aproximado de pessoas nestes bairros, segundo o IBGE (2012).

\section{e- Transporte Local e Sinalização}

Outro ponto a ser destacado é o alto número de veículos motorizados frequentando a área da Serrinha. Até recentemente, a maior parte dos frequentadores se deslocava a pé, mas atualmente, com a melhora do caminho de acesso, o número de visitantes que se utili- za de automóveis tem aumentando, gerando risco aos animais silvestres, às funções ecossistêmicas e, também, aos banhistas que estejam caminhando por tal trilha.

Outro fato curioso a ser mencionado refere-se à sinalização do local. Em nenhum dos pontos da trilha observa-se qualquer tipo de sinalização, constatando-se, mais uma vez, o despreparo local para o recebimento de turistas, banhistas e visitantes de forma geral.

Para diminuição destes impactos ambientais, sugere-se:

1. Parceria entre poder público, privado e sociedade civil, em especial ONGs e Associações de Moradores, pela preservação da área: não será somente com investimento econômico que será possível resolver o problema da Serrinha, é fundamental a união de todos em prol da preservação do local, com responsabilidade compartilhada entre o poder público e privado, mas gestão do IEF, que é o órgão responsável pelo PEIT.

2. Melhorar a fiscalização da área: contratação de vigias, cercamento e construção de Portarias, no bairro Cabanas e no distrito de Passagem, poderiam facilmente resolver o problema de incursões clandestinas, furto de espécies endêmicas, incêndios e assaltos a visitantes. Para tanto, cabe ao atual gestor, IEF, buscar parcerias com a polícia militar, florestal e comunidade local, de maneira a garantir uma gestão compartilhada capaz de levar segurança aos frequentadores.

3. O IEF precisa se fazer mais presente na gestão de sua área, seja através de parcerias público-privadas, seja através de aumento real do efetivo. Não se justifica um Parque Estadual, com potencial turístico e ecológico, ficar abandonado como este se encontra.

4. Mecanismos de Gestão Ambiental compartilhada: Parcerias geridas pelo IEF, em conjunto com a iniciativa privada, de maneira a se criar Programas de Educação Ambiental para a comunidade do entorno, devem ser pensadas, pois esta é uma das principais formas de conscientização ecológica acerca do uso sustentável dos recursos naturais.

\section{2 - Serviços Ecossistêmicos}

O Plano de Manejo do PEIT (IEF, 2013) apresentava, em uma de suas questões, qual a principal função ambiental que o Parque possuía, na opinião dos visitantes. Ali, $82 \%$ dos entrevistados responderam que a principal função, para eles, era a preservação ambiental e o que o PEIT apresentava para tal premissa era suficiente.

Para aqueles que não concordavam com a premissa de suficiência do PEIT, os argumentos mais presentes foram: a necessidade de se investir mais em educação ambiental e maior integração entre os poderes executivo estadual e municipal.

Faz-se importante colocar que, mesmo respondendo 
ao questionamento acerca de funções ambientais, nem sempre os entrevistados possuem total entendimento do que está sendo questionado, exemplo disso é o estudo de Oliveira Junior et al (2012), em que 51,20\% da população do entorno respondeu conhecer o que é o beneficio provido pelo PEIT, resultado alto, apesar de representar pouco mais da metade dos entrevistados.

Neste estudo, consideram-se funções ambientais aquelas capazes de gerar benesses diretas e indiretas ao ser humano (HUETING et al, 1997), através de um determinado serviço, o serviço ambiental. Destaca-se, ainda, que estas nem sempre possuem uma única direção, sendo possível que sejam produto de mais de um serviço e vice versa (COSTANZA et al, 1997).

Estes conceitos são importantes para o poder público e a iniciativa privada verificarem se existe, ou não, a oferta de serviços ecossistêmicos em equilíbrio com os recursos naturais e se, uma vez recuperado os recursos naturais, ocorrerá uma retomada do equilíbrio anterior e a consequente oferta destes serviços (TOSTO et al, 2012)

Utilizou-se, neste trabalho, a descrição das funções ambientais proposta por Constanza et al (1997) e De Groot et al (1992), conforme as tabela 1 e 2.

Na tabela de Constanza et al (1997), estão presentes os serviços e funções ambientais, ou seja, aquilo que o ecossistema de determinado local é capaz de oferecer para a manutenção global dos biomas e os benefícios resultantes ao ser humano. Heal (2000) complementa apresentando os serviços e funções ambientais como sendo aqueles capazes de prover o mínimo de estrutura para sobrevivência dos seres humanos.

Portanto, pela tabela 1, observou-se como a área da Serrinha possui prerrogativas de interesse público, uma vez que apresenta todos os serviços propostos pelo autor.

A tabela 2, proposta por De Groot et al (1992) como continuidade da anterior, se propôs a organizar aquelas funções já apresentadas e observadas na área de estudo, contribuindo, portanto, para a discussão dos impactos das funções presentes em cada uma das categorias.

As funções de regulação são as capazes de manter um local e seus processos de interação ecológica de maneira equilibrada, garantindo o equilíbrio ecossistêmico (DE GROOT et al, 1992). No presente estudo observaram-se as seguintes funções de regulação: Regulação do Clima, dos Distúrbios, da Água, Controle de Erosão, Formação do Solo, Ciclo de Nutrientes, Tratamento de Resíduos, Polinização, Controle Biológico, Refúgio.

Já as Funções de Provisão são as que o local oferece como condições adequadas de uso, por parte da população, sem gerar impactos antrópicos significativos no sistema natural presente (DE GROOT et al, 1992). Na Serrinha, a única destas funções perceptíveis foi o Valor Recreativo (Recreação).

As Funções de Produção são os bens naturais presentes que podem ser utilizados, de maneira direta, pelo homem (DE GROOT et al, 1992), sendo observados no local: a Regulação de Gás, o Abastecimento de Água, a
Produção de Comida, de Matéria Prima e os Recursos Genéticos.

Por último, o quarto grupo é formado pelas funções de informação, que consiste nas vantagens psicológicas que o ativo natural pode favorecer (DE GROOT et al, 1992). Na área de estudo, o único presente é o Valor Cultural, que engloba, entre outros, a educação ambiental, o valor científico e a história do local.

A observação dos impactos, funções e serviços ecossistêmicos da área da Serrinha, de acordo com a metodologia de classificação de TEEB (2010), são importantes para se notar a quanto esta Cachoeira pode contribuir com a população local e os visitantes do PEIT, especialmente em relação ao valor cultural associado às funções de contemplação da paisagem, meditação, lazer, recreação e entretenimento, que é o principal motivo de procura do local atualmente.

\subsection{Valor Ambiental da Cachoeira da Serrinha segundo a Metodologia TEEB}

Após a caracterização das funções e serviços ambientais, passou-se para a Valoração do local segundo a Metodologia TEEB. Para tanto, transformou-se o valor do local, em geral em $\mathrm{km}^{2}$, para hectares (ha) e, em seguida, multiplica-se tal valor por $10^{-8}$ (adequação da base de cálculo). Neste caso, a área de estudo possui $6,587 \mathrm{~km}^{2}$ (SAAE, 2012).

Em seguida, identificam-se os biomas presentes no local. No caso da área da Serrinha, observou-se a presença dominante de três biomas principais: Florestas Naturais, Cerrado (Pastagens ou Savanas) e Lagoas. Por último, e não menos importante, realiza-se o processo de extrapolação com o uso da Tabela de Costanza (Tabela 5).

Devido à metodologia do TEEB não aprofundar em sua formulação matemática, optou-se por fazer transformação dos valores contidos na tabela original para o estudo da Serrinha. A transformação entre o Bioma e a Área se deu pegando o valor da área da Serrinha $(6,587$ $\mathrm{km}^{2}$ ), transformando-o em hectares e, posteriormente, multiplicou-o pelo número de referência da tabela $\left(10^{-8}\right.$ ), faltando apenas a porcentagem referente a cada bioma neste cálculo. Esta formula foi aplicada aos itens floresta, grama e pastagem natural e lagos e rios.

Em seguida, identificou-se a porcentagem referente às áreas estudadas. Optou-se por considerar o serviço terrestre com 100\% representado pelo seu valor total de 15.323. Com esta informação, pegou-se o valor referente às florestas e fez-se uma regra de três, simples, para identificar a relação entre este bioma e o serviço terrestre total $(4855 \times 100 / 15323=31,68)$, aplicando-se a mesma metodologia nos outros ecossistemas identificados na Serrinha ${ }^{2}$.

Neste ponto específico, basta realizar a transfor-

2 Porcentagem da área de florestas $(4855 \times 100 / 15323=31,68 \%)$, porcentagem da área de grama e pastagem $(3989 \times 100 / 15323=26,03 \%)$ e por fim porcentagem da área dos lagos e rios $(200 \times 100 / 15323=$ $1,30 \%)$. 
mação da área e da porcentagem em que cada bioma representa, multiplicando-se tais valores para identificar a relação entre o Método de Constanza e a Serrinha. Para se compreender Constanza, considera-se que, no mundo, a área referente às florestas tropicais possui o valor de 1.900 há x $10^{8}$ e o valor referente a Serrinha é de 0,000208705 há $\times 10^{8}$.

Com estes valores, o próximo passo é identificar os valores monetários para cada um dos 17 serviços ambientais. Neste ponto deve-se observar que a moeda original é o dólar e deve-se realizar sua transformação em reais.

Um ponto em que a tabela de Constanza não explica é a origem dos valores, referente aos valores finais de cada um dos 17 serviços ecossistêmicos, e, devido esta dificuldade de compreensão, utilizou-se nesta pesquisa um fator multiplicador que é referente ao somatório de cada um dos serviços ecossistêmicos dividindo-se o valor original da tabela.

Com posse destas informações, conseguiu-se calcular o valor monetário estimado da seguinte maneira:

Valor da área $\times 10^{8} \times$ Valor dos serviços ecossistêmicos x fator multiplicado x Valor do Real/Dolar ${ }^{3}$

De acordo com a metodologia proposta, basta fazer o somatório de todos os ecossistemas, tendo o valor am-

3 Exemplificando. Valor econômico regulação do clima $=0,000208705$ x $108 \times 223$ × 1,513274366 x 2,087 = R\$14.698.671,20 biental da Serrinha estimado em R\$ 73.196.258,93 (US\$ 34.913.550,64; segundo a cotação do dólar em 24-08-2013).

Oliveira Júnior et al (2012), em trabalho que buscava obter o Valor Ambiental (VA) do PEIT, encontrou R\$ 392.474.660,52 para os serviços ecossistêmicos. Pensando-se na extensão do PEIT como um todo, ou seja: 7.543 hectares, o valor encontrado, para 658,7 ha, é um valor altamente significativo.

Em outro trabalho no PEIT, Tafuri (2008) verificou um VA ecossistêmico de R\$ 1.976.869.440,00. Mais uma vez observa-se a relevância do local e a similaridade nos resultados, pois em nosso trabalho observou-se um valor pouco maior que $10 \%$ deste em uma área de, também, aproximadamente $10 \%$ do PEIT.

Outro estudo de VA relevante, e que merece ser citado, foi o de valoração do Parque Nacional da Lagoa Preta (PNLP), que encontrou os valores de R $\$ 321.472,00$ (BRAGA, 2003). Mais uma vez verifica-se o quanto a área da Serrinha possui valor econômico agregado, pois seu VA apresentou valores bem maiores que o encontrado no PNLP em área menor.

Evidentemente que esta metodologia, por se basear em valores já definidos e servir de parâmetro geral para os cálculos, pode apresentar incerteza em alguns pontos, entretanto, não se pode negar que esta metodologia tem sido cada vez mais utilizada quando se busca calcular o Valor Ambiental de um determinado bem ambiental, em especial aqueles onde a visitação se faz complicada.

Tabela 5: Valores encontrados no estudo realizado na área da Cachoeira da Serrinha.

\begin{tabular}{|c|c|c|c|c|c|c|}
\hline Bioma & Area (háx x 108) & 1-Regulação de gás & 2-Regulação do clima & - Regulação de pertubaçõe & 4-Regulação da água & 5-Suprimento de água \\
\hline 1.1 Tropical & 1900 & & 223 & 5 & 6 & 8 \\
\hline 1.2 Florestas -Serrinha & 0,000208705 & & 223 & 5 & 6 & 8 \\
\hline 2.1 Grama e pastagem natural & 3989 & 7 & 0 & & 3 & \\
\hline 2.1 Grama e pastagem natural - Serrinha & 0,000171478 & 7 & 0 & & 3 & \\
\hline 3.1 Lagos e rios & 200 & & & & 5445 & 2117 \\
\hline 3.2 Lagos e rios -Serrinha & $8,5975 \mathrm{E}-06$ & & & & 5445 & 2117 \\
\hline Valores em RS - Tropical & 6089 & $R \$ 0,00$ & $\operatorname{R} \$ 14.698 .671,20$ & $\operatorname{RS} 22.750,29$ & $R \$ 5.463,40$ & $\mathrm{R} \$ 43.582,52$ \\
\hline Valores em RS - Grama e pastagem natural & & $\operatorname{R} \$ 758.321,62$ & $R \$ 0,00$ & $R \$ 0,00$ & $\mathrm{R} \$ 2.244,44$ & $R \$ 0,00$ \\
\hline Valores em RS - Lagos e rios & & $R \$ 0,00$ & $R \$ 0,00$ & $R \$ 0,00$ & $R \$ 204.244,51$ & RS $475.098,79$ \\
\hline Bioma & Area (háx x 108) & 6-Controle de erosão & 7-Formação do solo & 8 Ciclos dos nutrientes & 9-Tratamento de residuos & 10- Polinização \\
\hline 1.1 Tropical & 1900 & 245 & 10 & 922 & 87 & \\
\hline 1.2 Florestas -Serrinha & 0,000208705 & 245 & 10 & 922 & 87 & \\
\hline 2.1 Grama e pastagem natural & 3989 & 29 & 1 & & 87 & 25 \\
\hline 2.1 Grama e pastagem natural - Serrinha & 0,000171478 & 29 & 1 & & 87 & 25 \\
\hline 3.1 Lagos e rios & 200 & & & & 665 & \\
\hline 3.2 Lagos e rios -Serrinha & $8,5975 \mathrm{E}-06$ & & & & 665 & \\
\hline Valores em RS - Tropical & 6089 & R\$ $16.612 .782,87$ & RS $744.680,05$ & RS $14.711 .561,04$ & $\mathrm{R} \$ 634.312,30$ & $R \$ 0,00$ \\
\hline Valores em RS - Grama e pastagem natural & & $\mathrm{R} \$ 1.615 .656,77$ & $\operatorname{RS} 61.184,94$ & $R \$ 0,00$ & $R \$ 521.168,23$ & $\operatorname{RS} 2.684 .056,23$ \\
\hline Valores em RS - Lagos e rios & & $R \$ 0,00$ & $R \$ 0,00$ & $R \$ 0,00$ & $R \$ 199.731,37$ & $R \$ 0,00$ \\
\hline
\end{tabular}


Tabela 5: continuação...

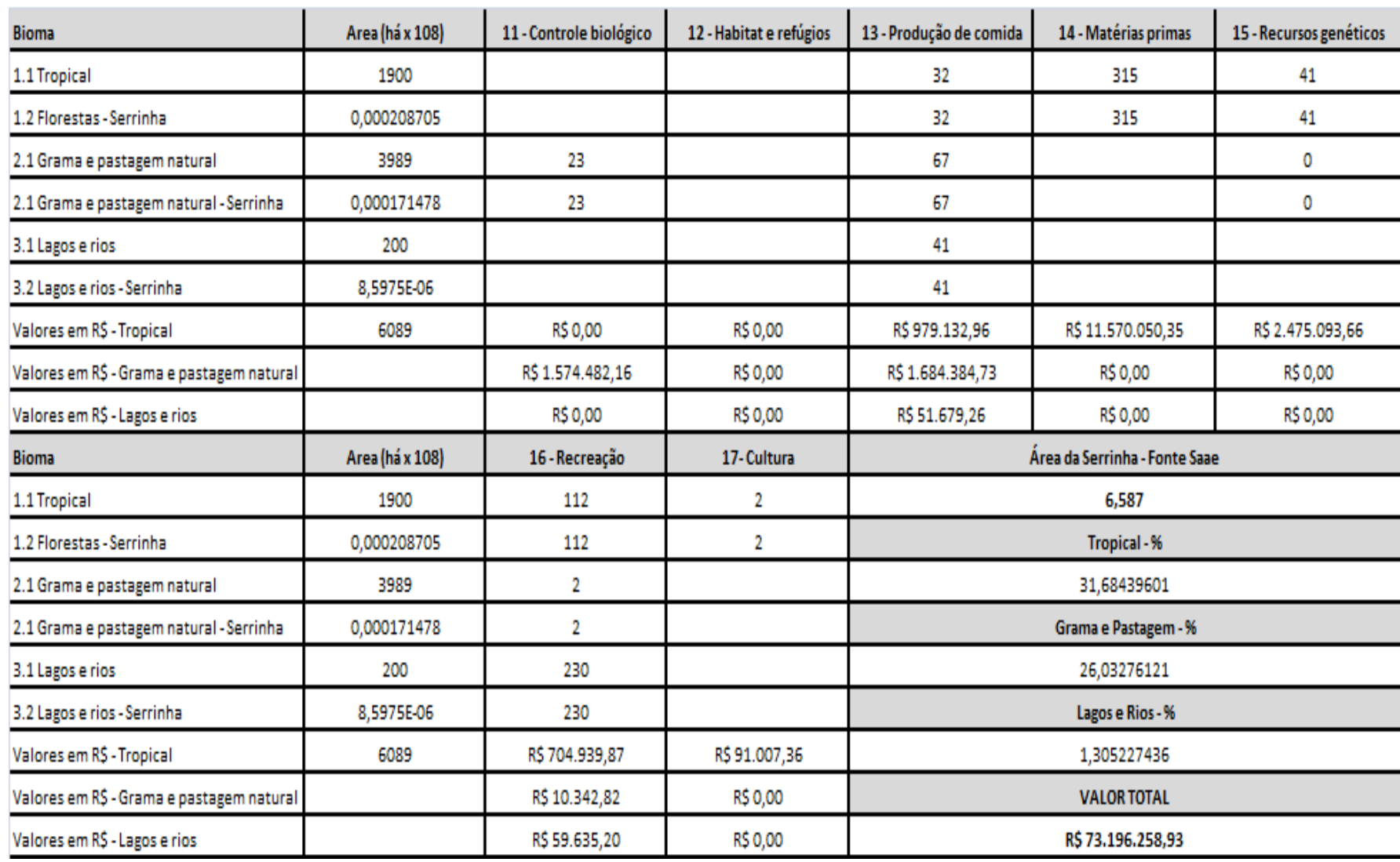

\section{Conclusões}

As UCs, atualmente, passam por inúmeras dificuldades de administração, gestão, fiscalização, segurança, apoio do poder público local, entre outros. Portanto, é importante o incentivo a estudos e pesquisas sobre a influência destas reservas nos municípios.

As Unidades de Conservação não possuem, ainda, um valor econômico-ambiental definido, sendo importante a descrição e valoração destas funções, pois isto pode contribuir significativamente para as Políticas Públicas nestas Unidades.

No caso do PEIT, especificamente em seu vetor norte, onde se realizou este trabalho, observa-se que os resultados desta pesquisa podem contribuir para sua preservação e uso sustentável, pois este é o primeiro estudo de Valoração Ambiental da região da Serrinha, em Mariana.

Acredita-se que os responsáveis pelo Parque do Itacolomi, que são o IEF, o governo do estado de Minas Gerais e a Prefeitura de Mariana, devam repensar a gestão do local, que, conforme se procurou demonstrar, encontra-se abandonado e mal cuidado.

Destaca-se, ainda, que estudos de valoração ambiental, por meio dos inúmeros métodos utilizados, somados às suas limitações econométricas, sociais e subjetivas, é algo recente nos projetos ambientais, apresentando van- tagens significativas em relação a outras metodologias, especialmente pelo fato de serem relativamente baratos e capazes de produzir resultados aceitáveis.

\section{Referências}

AB'SABER, A. N. Os domínios morfoclimáticos na América do Sul. Bol. Inst. Geogr. USP, São Paulo, 52: 1-21. 1977.

ANDRADE, D..; ROMEIRO, A. Capital natural, serviços ecossistêmicos, e sistemas econômicos: rumo a uma economia dos ecossistemas. Texto para discussão: I/E Unicamp, Campinas, n. 159, maio 2009. Disponível em: http://www.anpec.org. br/...on/.../000- ba8e809727ffdd88ec84852a8cd209fb. pdf Acesso em maio de 2013.

BALMFORD, A., BRUNER, A., COOPER, P., COSTANZA, R., FARBER, S., GREEN, R.E. ET AL. Economic reasons for conserving wild nature. Science, 397, 950-953. 2002.

BRAGA, B. Introdução à Engenharia Ambiental. 2.ed. São Paulo: Prentice Hall, 2003. 
BRASIL, 2008. Ministério do Planejamento, Instituto Brasileiro de Geografia e Estatística (IBGE). Divisão Territorial do Brasil e Limites Territoriais. Disponível em: <ftp://geoftp.ibge.gov.br/ Organizacao/Divisao_Territorial/2008/DTB_2008. zip> Acesso em: 14 de Agosto de 2009.

Ministério do Planejamento, Instituto Brasileiro de Geografia e Estatística (IBGE). Estimativas da população para $1^{1}$ de julho de 2009. Disponível em: <http://www.ibge.gov.br/home/ estatistica/populacao/estimativa2009/POP20 09 DOU.pdf> Acesso em: 14 de agosto de 2009.

Ministério do Planejamento, Instituto Brasileiro de Geografia e Estatística (IBGE). Censo da População de Mariana em 2012. Disponível em: <file://C:/Users/Pedro/Desktop/IBGE\%20Censo\%20 2010.htm> Acesso em Junho de 2013.

CASIMIRO FILHO, F. Valoração monetária de amenidades ambientais: algumas considerações. Teoria e Evidência Econômica. Passo Fundo, v. 7, n. 13, p. 53-68, 1999.

Comissão Mundial sobre Meio Ambiente e Desenvolvimento. Nosso futuro comum. Rio de Janeiro, Fundação Getúlio Vargas. 1987.

COMMON, M.; STAGL, S. Ecological economics: an introduction. Cambridge: University Press, 2005.

COSTANZA, R. DALY, H. E. Natural capital and sustainable development. Conservation Biology,v. 6, n.1, p. 37-46, 1992.

COSTANZA, R. Economia Ecológica: uma agenda de pesquisa. Em: MAY, P.H.e R.S. da Motta (organizadores), Valorando a Natureza: Analise Econômica para o Desenvolvimento Sustentável. Editora Campus, p.p. 111-140, 1994.

R., D'ARGE, R., DE GROOT, R.S.,

FARBER, S., GRASSO, M., HANNON, B., LIMBURG, K., NAEEM, S., O’NEILL, R.V., PARUELO, J., RASKIN, R.G., SUTTON, P., VAN DEN BELT, M., The value of the world's ecosystem services and natural capital. Nature 387, 253-260. 1997.

R.D'ARGE, R.DE GROOT FARBER, S., GRASSO, M., HANNON, B., LIMBURG, K., NAEEM, S., O'NEILL, R.V., PARUELO, J., RASKIN, R.G., SUTTON, P., VAN DEN BELT, M. The value of the world's ecosystem services and natural capital. Ecological economics. Vol. 25, p.p.3-15, 1998.
DALY, H. E. COBB JR., J. B. For the common good: redirecting the economy toward community, the environment, and a sustainable future. Boston: Beacon Press, 1989.

FARLEY, J., Ecological Economics: principles and applications. Island Press, Washington, DC. 2004.

DAILY, G., Nature's services: societal dependence on natural ecosystem. Island Press, Washington, DC. 1997.

DE GROOT, R. S. Environmental functions as a unifying concept for ecology and economics. Environmentalist 7, 105-109, 1987.

DURNING, A. B. Apartheid's environmental toll. Worldwatch Paper, 95, Washington. 1990.

EHRLICH, P. R. e EHRLICH, A. H. The value of biodiversity . Ambio. A Journal of the Human Environment, v. XXI, no 3, maio, pp. 219-26. 1992.

EVERETT, R.A. Patterns and pathways of biological invasions. Trends in Ecology \& Evolution, v. 15, p. 177-178, 2000.

GIL, A. C. Como elaborar projetos de pesquisa. 3. Ed. São Paulo: Atlas, 1994.

HEAL, G. Nature and the marketplace: capturing the value of ecosystem service. Washington: Island Press, 2000. 221p.

HUETING, R., REIJNDERS, L., de BOER, B., LAMBOOY, J., JANSEN, H., The concept of environmental function and its valuation. Ecological Economics 25, 31-35. 1998.

INSTITUTO ESTADUAL DE FLORESTAS (IEF). Parque Estadual do Itacolomi. Disponível em <http://www.ief.mg.gov.br/index.php?option=com_ conte $n t \% 20 \&$ task=view\&id=193\&temid=130> Acesso em Fevereiro de 2013.

MORENO, E. Brucellosis in Central America. Vet. Microbiol., v.90, p.31-38, 2002.

MOTA, J. A. O Valor da Natureza: economia e política dos recursos naturais. $2^{\underline{a}}$ edição. Rio de Janeiro: Garamond, 2006.

MARX, K. O Capital. O Capital [Livro I]. São Paulo: Ciências Humanas. 1978. 
NETO, G. K. Valoração Ambiental dos Recursos Naturais. Disponível em: http://www.geo-kas. blogspot.com.br/2010/09/valoracao-ambiental.html. Acessado em: 10 de Dezembro de 2012.

OLIVEIRA, J. A. P. Instrumentos econômicos para gestão ambiental: lições das experiências nacional e internacional. Série: Construindo os Recursos de Amanhã, v.3. Salvador: Centro de Recursos Ambientais: NEAMA, 2003.

PDUAM. Relatório Diagnóstico de Mariana. Equipe Consultora do Plano DiretorUrbano-Ambiental de Mariana. Inédito. 350p. 2003.

Relatório para negócios do TEEB (The Economics of Ecosystems and Biodiversity, A Economia dos Ecossistemas e da Biodiversidade) - Resumo executivo, 2010.

RBC. Revista Brasileira de Cartografia № 57/03, (ISSN 1808-0936). 2005.

SAAE Mariana. Serviço Autônomo de Água e Esgoto da Cidade de Mariana. Disponível em < http://www.saaemariana.com.br/index/secao. php? secao=5 $>$. Acesso em Novembro de 2013.

TAFURI, A. C. Valoração ambiental do Parque Estadual do Itacolomi, Ouro Preto, Minas Gerais, 2008. Belo Horizonte, MG. Dissertação Universidade Federal de Minas Gerais, DESA.

TEEB (2008). The Economics of Ecosystems and Biodiversity:An Interim Report, European Comission, Brussels. Disponível em: www.tee. orgbweb/LinkClick.asp x?fileticket=u2fMSQoWI

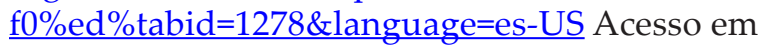
Fevereiro de 2013.

THE ECONOMIST. V. 323, no 7761, 30 de maio 5 de junho. 1992.

TOSTO, S. G. PEREIRA, L. C. MANGABEIRA, J. A. C. Serviços ecossistêmicos e Serviços ambientais: Conceitos e Importância. Disponível em: < file://C:/Users/Pedro/Desktop/ Servi\%C3\%A7os\%20ecossist $\%$ C3\%AAmicos $\% 20$ e\%20Servi\%C3\%A7os\%20ambientais\%20\%20 Conceitos\%20e\%20import\%C3\%A2ncia!\%20 artigo $\% 20$ de $\% 20$ S\%C3\%A9rgio\%20Gomes\%20T\%C3\%B4sto, \%20Lauro\%20Charlet $\% 20$ Pereira\%20e\%20Jo\%C3\%A3o\%20Alfredo\%20 de\%20C.\%20Mangabeira\%20\%20\%20Portal $\% 20$ EcoDebate.htm> Acesso em Agosto de 2013. 